\title{
Cape Verde: Growth and Poverty Reduction Strategy Paper II (2008-11) Joint Staff Advisory Note
}

The attached Joint Staff Advisory Note (JSAN) of the Poverty Reduction Strategy Paper - II for Cape Verde, prepared jointly by the staffs of the World Bank and the IMF, was distributed with the member country's Poverty Reduction Strategy Paper to the Executive Boards of the two institutions. The objective of the JSAN is to provide focused, frank, and constructive feedback to the country on implementing its Poverty Reduction Strategy (PRS).

Copies of this report are available to the public from

International Monetary Fund • Publication Services

$70019^{\text {th }}$ Street, N.W. • Washington, D.C. 20431

Telephone: (202) 623-7430 • Telefax: (202) 623-7201

E-mail: publications@imf.org•Internet: http://www.imf.org

\section{International Monetary Fund Washington, D.C.}





\title{
INTERNATIONAL DEVELOPMENT ASSOCIATION \\ AND \\ INTERNATIONAL MONETARY FUND
}

\section{CAPE VERDE}

\section{Growth and Poverty Reduction Strategy Paper II (2008-11) Joint Staff Advisory Note}

\author{
Prepared by the Staffs of the International Monetary Fund \\ and the International Development Association \\ Approved by David Nellor and Mark Plant (IMF) \\ and Obiageli K. Ezekwesili (IDA)
}

June 9, 2008

\section{OVERVIEW}

1. The Cape Verde authorities' second Growth and Poverty Reduction Strategy Paper (GPRSP-II) was completed in May 2008. The strategy covers the period 2008-11 and maintains the thrust of the GPRSP-I which was presented to the Boards of the International Development Association (IDA) and the International Monetary Fund (IMF) in January 2005. The GPRSP-II was prepared drawing on lessons learnt from the implementation of the first GPRSP and is based broadly on the same five pillars: (i) good governance, effectiveness and equity; (ii) human capital; (iii) competitiveness for privatesector-led growth; (iv) infrastructure and land use management; and (v) social cohesion.

\section{Important progress has been made in achieving a number of objectives set forth} in the GPRSP-I, but the monitoring and evaluation framework needs further improvement. Since the inception of the GPRSP-I, and despite the challenges in the energy sector, robust economic growth, underpinned by good reform and social policies, has contributed to poverty reduction. Moreover, Cape Verde became a special-partner of the European Union in October 2007; was invited to join the WTO in December 2007; and graduated to the United Nations' category of medium-developed country (MDC) in January 2008. The government has also made progress in public financial management, including budget execution and monitoring; achieved virtually universal primary education; and expanded the access to health care, among others. However, progress in the implementation of the monitoring and evaluation (M\&E) system for the GPRSP-I did not fulfill the expectations of its original design. While improved, this remains an area that needs further efforts as indicated below (paragraph 26).

3. The preparation of the GPRSP-II was inclusive. It was prepared by the Technical Secretariat for Development Assistance, at the Ministry of Finance and Public 
Administration, which worked in close collaboration with the line ministries. This resulted in a strong ownership of the strategy by the government. Furthermore, a communication strategy was developed and consultations were held with municipalities, civil society, and the private sector in Santiago, São Vicente and Sal Islands. However, the strategy could have specified the major issues raised during the participatory process, if any, and whether earlier drafts were amended to take these issues into consideration. Going forward, staffs recommend effective involvement of all the actors in the implementation stage of the GPRSP-II.

4. The GPRSP-II is a comprehensive strategy covering most of the challenges and areas of action to foster growth and reduce poverty. Staffs recommend that the authorities further link objectives to actions articulated around outcome indicators as part of the GPRSPII implementation.

\section{Poverty Trends and Diagnosis}

\section{Important progress was made in poverty reduction but rural poverty still} remains high. The strategy reports that Cape Verde is on track to meet the Millennium Development Goal (MDG) of halving extreme poverty by 2015. The MDG of halving poverty will be met provided that the annual growth rate is at least 5 percent on average. Real per capita GDP grew by 5 percent during the implementation of the GPRSP-I (2004-7), and unemployment fell by 6 percentage points to 18 percent in 2005-06 alone. Although the poverty diagnosis in the strategy could be deepened, it reveals that the share of the population in poverty declined by around 9 percentage points (from 37 percent to 28 percent) between 2001-02 and 2006. ${ }^{1}$ However, despite progress made to date, the gap between urban and rural income growth is still wide; thus, efforts to raise rural incomes further and a more effective design of social inclusion programs are needed.

6. Staffs recommend enhanced monitoring of income inequality. While some indicators on poverty are presented, the strategy has no information on income concentration and income distribution across islands, which is critical given the strong disparities. The release of the 2007 household survey (QUIBB) results will be crucial to the elaboration of the first progress report for the GPRSP-II. In this respect, staffs recommend that an in-depth analysis be carried out in order to assess where the poverty pockets are. Technical problems have delayed the completion of the survey, but results are expected to be ready by end-June 2008.

\footnotetext{
${ }^{1}$ Based on the value-of-possessions criterion. Results computed by staffs based on the 2006 QUIBB.
} 


\section{Macroeconomic Policies ANd Framework}

7. Despite frequent droughts and problems in the energy sector, Cape Verde's macroeconomic performance remained strong and the policy framework underpinned by the exchange rate peg was supportive of GPRSP-I goals. Real per capita GDP has increased on average by over 7 percent a year since 2001, faster than most small island economies and the average for sub-Saharan Africa. In 2006, real GDP growth reached double digits, boosted by tourism, telecommunications, and construction. Staffs estimate that GDP grew by about 7 percent in 2007 and, factoring in the effects from the global economic slowdown, growth is expected to moderate only slightly in 2008 as tourism and construction continue to expand. During December 2007-March 2008, twelve month inflation averaged about $3 \frac{1}{2}$ percent, broadly in line with inflation in the Euro area. Fiscal policy and monetary management are promoting external stability, and the exchange rate peg has served Cape Verde well as an anchor for financial stability.

8. The implementation of the GPRSP-II could benefit from an improved analysis of the developments underpinning macroeconomic projections. Staffs recommend that future projection exercises make explicit the linkages among exports, growth, rising investment, and the external current account. This will enable better judgment of the realism and consistency of the macroeconomic projections. Staffs recommend that alternative macroeconomic scenarios (including for externally-funded public investments) be regularly considered, and discussed in future Annual Progress Reports (APRs). By the same token, staffs recommend that projections take into account the risks to the macroeconomic outlook, including the ongoing global slowdown given Cape Verde's highly open economy.

9. Staffs concur with the strategy's assessment that the success of the GPRSP-II implementation hinges on preserving macroeconomic stability and debt sustainability. The GPRSP-II explicitly recognizes that preserving macroeconomic balance is a condition for sustainable growth and that fiscal policy is critical for stability. Given the rapidly changing balance of payments picture for Cape Verde, the strategy correctly emphasizes the importance of securing external funds on favorable terms, and the need to continue to build up international reserves. However, to create fiscal space, staffs recommend that the domestic debt be further reduced to below 20 percent of GDP in line with the Joint BankFund Debt Sustainability Analysis conducted in 2007. ${ }^{2}$ In addition, given the importance of nonresident deposits for financial stability, future APRs could address in detail developments in the area of financial soundness.

10. While staffs support the thrust of the macroeconomic policies in the GPRSP-II, they note possible risks. The projected double-digit growth rates in the outer years of the strategy, led by private investment and supported by an increase in externally-funded public

\footnotetext{
${ }^{2}$ IMF Country Report 08/37.
} 
investment in infrastructure, is more optimistic than the staffs' projections and no alternative scenarios are discussed in the strategy. A double digit growth rate occurred only in 2006 in Cape Verde owing largely to one-off events. Going forward, staffs urge that prudence in fiscal policy be continued. Staffs also recommend assessing the implication of the large public investment program for the underlying fiscal position. In this context, it will be critical to conduct mid-year reviews of fiscal developments and implement fiscal policy based on a medium-term fiscal framework. These efforts could be supported with the use of regularly updated and detailed macroeconomic and sectoral tables to better assess the consistency of the macroeconomic framework with the overall strategic goals.

\section{Sectoral Policies}

\section{A. Public Sector Governance}

\section{Staffs agree with the emphasis placed in streamlining the administrative} structure. To this end an Action Plan was set out in the Prime Minister's Resolution of December 2007 and implementation has started. With regard to the civil service reform that is under way, staffs recommend careful analysis of the fiscal impact of the implementation of the new wage structure, which lays out a new career and salary system. Furthermore, staffs concur with the need to reinforce the state's regulatory capacity and strengthen its oversight role.

\section{Ethic and transparency are appropriately discussed in the strategy. It indicates} that these two objectives will be pursued by improvements in public financial management. Staffs recommend that high priority be placed on strengthening audit functions. The state general accounts have been sent to the Court of Auditors (TdC) with delays, although progress has been made in clearing backlogs. Furthermore, staffs urge the final approval of the new TdC Law and its implementation decrees to improve transparency and accountability. Staffs also recommend that the human and financial resources of the internal audit department (IGF) be strengthened and its risk based methodology enhanced.

\section{The importance of the implementation of the new procurement code is} emphasized in the strategy. Its implementation is critical in the context of the increasing number of public investments in the country, particularly related to infrastructure. Staffs recommend that the new procurement regulatory agency be staffed fully. This will also contribute to reduce the costs of goods and services which is needed for a disciplined fiscal policy.

14. Recent improvements in public financial management will allow a better linkage between GPRSP-II and domestic processes for the elaboration of the annual budget. The budget software SIGOF has been expanded to line ministries, public agencies and some municipalities, which has allowed the decentralization of some phases of budget execution. 
Furthermore, the existence of sectoral medium-term expenditure frameworks (MTEFs) done in close coordination with the elaboration of GPRSP-II and the strong engagement of line Ministries in the GPRSP-II preparation process will help ensure that the annual budgets are in line with the priorities set forth in the strategy. Staffs reiterate the urgency to approve the new Budget Framework Law to legally require the annual update of the MTEF. Staffs also recommend that the MTEF be a top-down instrument to allocate resources, rather than a bottom-up procedure that simply adds sectoral budgets.

\section{B. Human Capital}

15. Staffs note that the overall performance of the education sector has been good. Most education indicators continued to follow a positive trend. Having virtually achieved universal primary education, Cape Verde is now gradually shifting its focus on improving quality and efficiency of education, expanding access to secondary education, restructuring and developing technical and vocational training, and developing tertiary education. Staffs agree that these are important issues to address in order to fully align the education and training system with the labor market and to respond to the needs of the economy. Among the priorities, staffs recommend particularly that the student learning assessment be put in place to track learning achievements of students in primary and secondary level, and that efforts be undertaken to gradually decrease the repetition rate in these levels of education. The proposed double-digit targets on repetition rate (10 percent for primary education and 18 percent for secondary education) still remain high, and more ambitious targets would greatly benefit efficiency and quality.

\section{Staffs agree with the strategy on the need to further improve quality and} increase access to health care services by the poor. Staffs note that strategic pillar II Human Capital does not include a strategy for the health sector. Although health indicators have progressed, staffs recommend that the authorities set more detailed quantitative goals for the sector. In terms of child health, Cape Verde still needs to strengthen its immunization system by expanding coverage, introducing cost/effective new antigens, and renewing its 10year old cold chain. Furthermore, staffs recommend that emphasis be put on improving access to Emergency Obstetric Care in order to reach the health MDGs. There have been significant improvements in terms of availability of general practitioners and specialists but the lack of nurses remains an issue. To improve access, staffs recommend expansion of health infrastructure, particularly in remote rural areas, training and deploying health personnel to these areas, and prioritizing the financing and provision of services for those diseases that have the most impact on the poor. Also, staffs recommend that financial support for access to health care by vulnerable groups be enhanced. 


\section{Infrastructure ${ }^{3}$}

17. The GPRSP-II describes the criticality of the energy sector for both growth and poverty reduction in Cape Verde. Staffs concur with the central objective of the energy sector policy to develop a modern and efficient sector capable of supplying the energy needed for growth, competitiveness, and welfare improvements.

18. Recent measures taken by the government to improve the regulatory framework for energy pricing indicated in the strategy are welcome. However, staffs recommend that the government accelerate the implementation of its comprehensive energy sector reform. In particular, staffs note that timely adjustment of tariffs and further financial assistance to the water and electricity company (Electra) will be necessary to allow it to implement its investment program, restore its creditworthiness with oil suppliers, and clear its arrears with spare-part suppliers. Tariff adjustments would also avoid contingent liabilities for the State.

19. The strategy recognizes the crucial role of infrastructure. Driven by a strong commitment to offer access to basic services to the whole population, infrastructure delivery has come a long way in terms of overcoming some challenges imposed by geography and nature. The challenge ahead is to keep up with the needs accentuated by the fast-growing tourism industry and to ease constraints imposed by infrastructure bottlenecks. Staffs recommend that, as more public resources are going to be deployed, a better management of the existing assets be ensured. Staffs also recommend that, as the authorities implement the strategy, they clarify the directions to improve service provision at a competitive and efficient rate, particularly with regard to the transportation and energy sectors, including through: (i) the planning of new infrastructure investments framed in the context of a MTEF; (ii) cost-benefit analysis and consistency with debt sustainability; (iii) feasibility assessment (market prospects) of expanding infrastructure; (iv) partnering with the private sector as a way to reduce fiscal risks and free-up public resources; and (v) provision in the budget for the recurrent costs that emerge from new investments. In this context, staffs note that the strengthening of the regulatory framework for PPPs would help mobilize resources for much needed investment and reduce the fiscal risk for the State.

\section{Staffs agree with the need indicated in the strategy to upgrade infrastructure}

while taking due care of the environment. Staffs reiterate the need to address the limited progress in the policy framework for environmentally sustainable tourism development. Environmental protection is essential to sustain an expanding tourism sector which has the country's natural attractions as its main comparative advantage. Staffs recommend that careful environmental analysis be conducted while implementing the GPRSP-II. Staffs also

\footnotetext{
${ }^{3}$ Key infrastructure sectors include water and sanitation, energy, and transports (ports, airports, and roads).
} 
note that enhanced transparency in the pricing, allocation and management of State lands will also be needed to safeguard the environment and fiscal assets.

\section{Competitiveness and Private Sector Development}

21. Overall, the GPRSP-II appropriately emphasizes private sector-led growth to reduce poverty. The policy environment to support private sector activity includes a comprehensive reform of the energy sector to ease infrastructure bottlenecks, a modernized state, improved competitiveness, and enhanced human capital.

22. The strategy describes the measures that the authorities are pursuing to improve competitiveness and the business climate. These include reforms to reduce the cost of doing business, improve labor market flexibility, and strengthen regulatory frameworks in areas such as energy and telecommunications. The recent opening of the Citizen House will strengthen the business environment and facilitate entrepreneurship by, for instance, reducing the time to start a business from 52 days to 1 (something not yet reflected in the 2008 investment climate indicators). Staffs recommend that the authorities address other issues raised related to the cost of doing business, notably on rigidities, which currently encourage informality. In addition, staffs agree that modernizing and increasing competition in the financial sector will support the private sector, including by strengthening supervision and regulation of banks.

\section{The strategy acknowledges the importance of tourism as the main source of} growth. It proposes measures to improve quality and diversify tourism services. Staffs agree with the role of tourism for the economy, but point out the need to diversify the overall export base to enhance the economy's resilience to shocks. To this end, staffs recommend that the forthcoming tax reforms take into account the need to diversify the economy. Policies to diversify could draw on the conclusions of the Diagnostic Trade Integration Study (DTIS) being conducted through the Integrated Framework agency consortium. Furthermore, the GPRSP-II emphasizes that fisheries resources are under tapped and that the potential of the sector for growth and poverty reduction is high. However, according to recent studies the potential of the sector is limited and in most cases resources have been fully or over exploited. Staffs recommend that the information provided by recent studies, including the 2007 World Bank Fisheries report, be used to reassess the potential and options in the fisheries sector.

\section{E. Social Services and Social Cohesion}

\section{Staffs recommend further decentralization and rationalization in the delivery of} social services. There has been little progress in this area pending the approval of the new Organic Law on decentralization. Staffs urge the approval and implementation of revised protocols of agreement for decentralized social services in all municipalities once the Organic Law on decentralization is approved. Staffs recommend developing human resource 
and financial management capacities in municipalities and monitoring progress in this area with an M\&E system.

25. The strategy correctly highlights the need for a food security plan. The recent increase in international food prices has not yet had an impact on domestic prices, as indicated in the strategy, owing to the large stocks of cereals. As these stocks are reduced, prices may increase, but this is not likely to threaten fiscal or external stability in the short term given the fiscal space and comfortable level of international reserves. The increase could however affect vulnerable groups and poor areas of the country, especially because of the expected increase in transportation costs due to high oil prices. The measures envisaged in the strategy to mitigate the impact of possible future increases comprise the elimination of international trade taxes and VAT on cereals and improvements in importation efficiency. Additionally, the authorities indicated that direct cash transfers could be increased and the eligibility rule for transfers relaxed. Staffs recommend the use of direct cash transfers instead of policies that distort market prices. Cape Verde has a number of programs that could be scaled up or adapted to respond to the present challenge, including by conditioning the direct cash transfers in the participation on health and education programs. In this context, staffs recommend a comprehensive analysis of the poverty impact of future possible increases in food prices across different groups to identify the neediest and better target the cash transfers.

\section{Implementation, Monitoring And Evaluation (M\&E), AND IMPLEMENTATION RISKS}

\section{While the GPRSP-II is elaborated on a results based framework, the strategy is} not explicitly linked to the achievement of these goals. Establishing a link between the sectoral strategies and the definition of clear and measurable indicators is critical for the monitoring and evaluation of the implementation of the GPRSP-II. Furthermore, it is important to ensure the alignment between indicators of the GPRSP-II, the Transformation Agenda, and the General Joint Matrix for Budget Support. The pilot-project of the M\&E system discussed in the GPRSP-II presents a wide range of output and outcome indicators that could benefit from some streamlining. Going forward, implementation could be strengthened by increasingly focusing on monitoring outcome indicators and incrementally adjusting the M\&E system. To strengthen the monitoring of the GPRSP-II, staffs also recommend that APRs be produced timely and possibly incorporate an analysis of poverty reduction expenditures allocated in the annual budget.

27. Risks remain regarding the implementation of the strategy. The major sources of risk relate to:

- Given the specialization in tourism, the global slowdown combined with the narrow export base can have knock-on effects on Cape Verde's external demand (including tourism) and FDI flows; 
- Given the reliance of the financial sector on nonresident deposits and the unclear degree of the interest-rate sensitivity of these deposits, they may be a potential capital account-based source of vulnerability;

- Although improvements have been made on energy pricing regulation, implementing the broader energy sector reform is likely to be a challenge. There is a need to press on to reduce fiscal risks and contribute to create fiscal space for infrastructure development.

- A sharp increase in food and fuel prices could delay further poverty reduction, especially in rural areas, given that most of the food and all oil has to be imported.

\section{Capacity constraints could also hamper the pace of implementation of the} strategy. There are risks associated with a relatively weak administrative capacity. For instance, there is a need to increase the resources allocated to the debt management office at the Ministry of Finance, to enhance its ability to monitor public debt, conduct regular debt sustainability analysis, and advise on debt management strategy. Also, efforts to strengthen M\&E capacity are needed to ensure adequate monitoring of the GPRSP-II implementation. While Cape Verde continues to benefit from external technical assistance for capacity development in several areas, including from the World Bank and the IMF, staffs recommend building appropriate mechanisms to secure transfer of knowledge and retention of experienced and competent staff to carry forward the agenda in the GPRSP-II.

\section{CONCLUSIONS AND ISSUES FOR DISCUSSION}

29. Cape Verde has made major strides in the last several years in achieving the key objectives set out in the GPRSP-I and in improving the well being of its citizens. The GPRSP-II sets out Cape Verde's medium-term goals and provides a comprehensive and integrated strategy for achieving those goals. As the authorities sharpen their strategic focus and strengthen the implementation of the GPRSP-II, they would benefit from addressing the following challenges highlighted earlier in this assessment:

- Maintaining an appropriate macroeconomic framework that takes into account the country's macroeconomic and fiscal risks; the importance of this cannot be overemphasized given Cape Verde's exchange rate peg and a small open economy that remains vulnerable to external shocks;

- Translating the key priorities identified in GPRSP-II into concrete and adequately costed expenditure plans that balance development needs and macroeconomic risks;

- Improving access to social services in line with the general expectations of an expansion of public service delivery. Their sustainability will need to be supported by improved targeting and enhanced cost recovery. 
30. Staffs look forward to Annual Progress Reports in the near future. Staffs recommend that future updates: (i) identify realistic and measurable targets, and (ii) improve the evaluation mechanism vis-à-vis the benchmarks set out in GPRSP-II.

31. In consideration of the GPRSP-II and associated JSAN, Executive Directors' views are sought on whether they agree with the main areas identified by staffs as priorities for strengthening the strategy and its implementation, and areas identified as key implementation risks. 